\title{
Orientaçào, arquitetura e construção dos ninhos de Synoeca surinama (L) (Hymenoptera; Vespidae) ${ }^{(*)}$
}

\author{
E. G. Castellón ("*)
}

\begin{abstract}
Resumo
Estudados os seguintes aspectos de Synoeca surinama (L): o "habitat" da espécle, preferências mostradas na escolha do ângulo de orientação do ninho e o ângulo de inclinação do substrato como proteção; a construção do ninho em etapas, seguindo padrōes característicos como a forma e expansão das células-base; a padronização no levantamento, medidas e forma do invólucro, a partir das paredes das células-base mais periféricas, as quais formam arco na margem externa e a abertura de acesso circular que é o ponto de referência na finalização da construção do invólucro até seu encerramento. Relaciona-se também o material usado na construção e a arquitetura do ninho como estratégia de defesa para a proteção da cria contra a preda. ção e parasitismo.
\end{abstract}

\section{INTRODUÇÃO}

Existem nas Américas (do México a Argentina) aproximadamente 380 espécies de vespas sociais agrupadas em vinte gêneros, (Richards \& Richards, 1951; Richards, 1971 e 1978; Jeanne, 1972). A maioria destas espécies não têm sido estudadas, quanto à arquitetura e construção do ninho, seja do ponto de vista da biologia experimental na tentativa de dar respostas à origem e à regulação da vida social.

Synoeca surinama é uma vespa social que ocorre geralmente nas florestas neo-tropicais, construindo ninhos sobre caules e galhos de árvores. Os ninhos desta espécie podem ter uma ou várias câmaras cobertas pelo invólucro.

S. surinama é um componente da entomofauna do Brasil onde se conhece pelo nome de "caba tatu", em virtude de o invólucro do ninho ser semelhante à couraça de um tatu (Dasypus sp.) (Ducke, 1904).
Este trabalho têm como objetivo proporcionar informações sobre a organização de arquitetura, materiais usados e construção dos ninhos de Synoeca surinama abordando aspectos da ecologia, comportamento e adaptações evolutivas dadas as condições dc ambiente.

\section{MATERIAIS E MÉTODOS}

Os dados e observaçōes de campo para elaborar este estudo sobre $S$. surinama foram coletados e realizados nas seguintes localidades: sede do Instituto Nacional de Pesquisas da Amazônia - Manaus $\left(03^{\circ}, 08^{\prime} \mathrm{S}, 60^{\circ} 01^{\prime} \mathrm{W}\right)$ no Estado do Amazonas; Fazenda Taperinha, sobre o paraná Ayayá ou Mayca $\left(02^{\circ} 25^{\prime} \mathrm{S}, 54^{\circ}\right.$ $\left.25^{\prime} \mathrm{W}\right)$ a $40 \mathrm{~km}$ de Santarém e Maicuru $\left(02^{\circ}\right.$ $\left.20^{\prime} \mathrm{S}, 54^{\circ} 20^{\prime} \mathrm{W}\right)$ Município de Monte Alegre a $67 \mathrm{~km}$ de Santarém no Estado do Pará. Existe uma coleta de Monte Dourado, ao longo do rio Jarí no Pará. Todas as localidades encontramse sobre uma faixa de 30 a $40 \mathrm{~m}$ acima do nível do mar. O tipo de clima é tropical. Para dados sobre temperaturas e índice de pluviosidade ver Jeanne (1972), Góes (1976) e Boletim Meteorológico do Instituto Nacional de Pesquisas da Amazônia (INPA).

Os resultados estão baseados nas observações de campo, coleta de ninhos com colônias, análises das colônias e coleta de ninhos abandonados.

Foram coletados 54 ninhos (três dos quais foram dados por W. Overal e R. Jeanne). Vinte e seis ninhos estavam habitados pelas respectivas colônias e 28 estavam abandonados; dos 28 ninhos abandonados, 6 encontravam-se

(") - Pesquisa financiada pelo CNPq-INPA, projeto Pós-Graduação.

(*) - Instituto Nacional de Pesquisas da Amazônia; Manaus. 
em boas condições, por terem sido coletados dois ou três dias depois de serem abandonados pelas colônias, e os outros 22 encontravam-se em condições insatisfatórias e ofereciam poucos dados ecológicos observáveis como: altura do solo, tipo de vegetação, ângulo de orientação e ângulo de inclinação do substrato.

O ângulo de orientação dos ninhos foi medido com uma bússola tomando como ponto de referência zero o norte magnético e como ponto de orientação no ninho a abertura de acesso e parte mais central do ninho. $O$ ângulo de inclinação do substrato foi medido com um transportador que se fixava ao substrato, uma corda com um extremo na parte central do transportador e no outro extremo um peso de chumbo de $5 \mathrm{~g}$. O sistema atuava como um pêndulo, que ao ficar imóvel indicava no transportador o grau de inclinação do substrato.

As observações comportamentais de $S$. surinama foram realizadas in situ e para tal foram marcados os indivíduos sobre o noto do tórax e abdômen com tintas tipo acrílico de diferentes cores. As marcas obedeciam a um código pessoal e foram aplicadas geralmente sem anestésico, embora fosse usado éter sulfúrico em alguns casos.

Para coletar as colônias, foi colocado um pedaço de algodão embebido por clorofórmio na abertura de acesso ao ninho, posteriormente foi serrado o galho-substrato e coletados o ninho e a colônia conjuntamente, a coleta de ninhos com colônias se realizava a noite quando toda a população de adultos se encontrava no ninho.

As medidas do ninho foram tomadas também in situ; o comprimento do invólucro do ninho foi medido em sua parte mais central. A largura do ninho foi medida no terço superior do invólucro, que é a parte mais ampla.

Foram observados quatro ninhos (ninhos 1, 2, 19 e 29) em processo de construção. As observações foram feitas nos ninhos 1 e 2 com ajuda de bînóculos; entretanto, nos ninhos 19 e 29 foi observada a construção a uma distância entre 0,2 a $0,5 \mathrm{~m}$.

\section{RESULTADOS}

\section{Habitat}

Synoeca, segundo Vesey-Fitzgerald (1938) é comum em selvas tropicais e seus ninhos são também abundantes em matas secundárias bem estabelecidas. Bodkin (1917 em Richards \& Richards, 1951] citou que na Guiana é comum encontrar $S$. surinama em áreas costeiras mais do que no interior, sendo esta observação comprovada por Richards \& Richards (1951).

Nas áreas onde esta pesquisa foi realizada, as colônias foram localizadas em: A selva tropical primária

B - matas secundárias bem estabelecidas,

C - também, tem-se encontrado ninhos de $S$. surinama em árvores plantadas próximo a prédios.

$\mathrm{Na}$ tabela 1 , indicam-se os locais das coletas, altura dos ninhos em relação ao solo onde são encontrados, tipo de vegetação, o tipo de substrato em que se encontraram os ninhos, isto é se sobre um ramo lateral se sobre um caule principal, as medidas do perímetro do substrato superior (medida circular do ramo substrato, tomada imediatamente acima do ninho) e do perímetro do substrato inferior (medida circular do ramo substrato, tomada imediatamente abaixo do ninho), a proteção decorrente da presença de ramificações da árvore substrato. A proteção pode ser: a) simples quando o substrato não tem ramificações até $50 \mathrm{~cm}$ acima do ramo onde se encontra o ninho, ou b) bifurcada, quando existem ramificações a menos de $50 \mathrm{~cm}$ do ninho que trazem maior proteção.

Ângulo de orientação do ninho de S. surinama

Dos 54 ninhos coletados, em 53 me foi possível medir o ângulo de orientação tomando como ponto de referência o norte magnético. O ponto de orientação do ninho foi a boca de acesso (situada na parte superior do ninho e projetada para fora) e a parte central do ninho (quilha). A fig. 1 mostra os resultados dos dados coletados. Observa-se então que os ni- 
TABELA 1 - Local da coleta, altura do ninho em relação ao solo (m), tipo de vegetação, tipos de substrato, medidas $(\mathrm{cm})$ do perimetro superior e inferior do substrato e proteção dos ninhos de $\mathrm{S}$. surinama. 1 = Sede do Instituto Nacional de Pesquisas da Amazônia, Manaus-AM. FT = Fazenda Taperinha, Santarém.PA. $M=$ Monte Jari, PA. $B=$ bosque secundário bem estabelecido. $C=$ bosque secundário em implantaçăo $(=$ capoeira $)$. $\mathrm{RL}=$ ramo lateral. $\mathrm{CP}=$ caule principal. $\mathrm{R} 3 \mathbf{3}=$ ramificação simples. $\mathrm{RB}=$ ramificação bifurcada. $\mathrm{SI}=$ sem informação.

\begin{tabular}{|c|c|c|c|c|c|c|c|}
\hline \multirow[b]{2}{*}{ Ninho } & \multirow[b]{2}{*}{ Local da coleta } & \multirow[b]{2}{*}{ Altura (m) } & \multirow[b]{2}{*}{ Vegetaçăo } & \multirow[b]{2}{*}{ Substrato } & \multicolumn{3}{|c|}{ Perímetro do substrato } \\
\hline & & & & & superior & inferior & proteção \\
\hline 1 & 1 & 5,0 & C & $R L$ & 38,0 & 30,0 & RS \\
\hline 2 & i & 7,6 & C & $R L$ & 24,0 & 23,0 & RS \\
\hline 3 & 1 & 6.4 & C & RL & $\mathrm{Si}$ & SI & RS \\
\hline 4 & i & 9,6 & C & $\mathrm{RL}$ & 39,0 & 30,0 & RS \\
\hline 5 & 1 & 11,5 & C & RL & 57,0 & 47,5 & RS \\
\hline 6 & FT & 5,4 & C & RL & 57,5 & 84,0 & RB \\
\hline 7 & $\mathrm{FT}$ & 2,8 & C & $\mathrm{CP}$ & 24,0 & 24,5 & $\mathrm{RB}$ \\
\hline 8 & FT & 1,6 & B & $\mathrm{RL}$ & 25,0 & 25,0 & RB \\
\hline 9 & FT & 4,0 & C & $\mathrm{CP}$ & 80,0 & 77,0 & RB \\
\hline 10 & $\mathrm{FT}$ & 3,5 & C & ripa & 5,0 & 5,0 & RS \\
\hline 11 & $\mathrm{FT}$ & 3.0 & C & ripa & 5,0 & 5,0 & RS \\
\hline 12 & $\mathrm{FT}$ & 1,5 & $\mathrm{C}$ & $\mathrm{CP}$ & 80,0 & 77,0 & RB \\
\hline 13 & FT & 20,0 & $\mathrm{C}$ & $\mathrm{CP}$ & 109,0 & 105,0 & RB \\
\hline 14 & $M$ & 1,7 & C & CP & SI & $\mathrm{SI}$ & RS \\
\hline 15 & $M$ & 3,5 & C & $\mathrm{CP}$ & Si & si & RB \\
\hline 16 & M & 2,5 & B & $\mathrm{RL}$ & Si & SI & RB \\
\hline 17 & $M$ & 1,5 & B & $\mathrm{CP}$ & SI & SI & RS \\
\hline 18 & $M$ & 2,0 & C & $R L$ & Si & SI & RS \\
\hline 19 & $M$ & 1,8 & C & $\mathrm{CP}$ & 30,5 & 30,5 & RS \\
\hline 20 & $M$ & 1,5 & B & RL & 28,0 & 27,5 & RS \\
\hline 21 & $M$ & 1.6 & B & $R L$ & 41,0 & 41,5 & RS \\
\hline 22 & $M$ & 1,6 & C & RL & 48,5 & 51,0 & RS \\
\hline 23 & $M$ & 2,2 & C & RL & 33,5 & 33,0 & RS \\
\hline 24 & $M$ & 0,5 & C & RL & 22,0 & 24,0 & RS \\
\hline 25 & M & 3,0 & C & RL & 27,5 & 26,5 & $\mathrm{RB}$ \\
\hline 26 & M & 2,5 & C & RL & 38,0 & 37,0 & RS \\
\hline 27 & $M$ & 1,5 & C & $\mathrm{CP}$ & 45,0 & 45,5 & RS \\
\hline 28 & M & 1,5 & C & RL & 58,0 & 57,5 & RS \\
\hline 29 & $M$ & 2,0 & B & $\mathrm{CP}$ & 45,0 & 45,0 & RS \\
\hline 30 & M & 1,5 & B & RL & 25,0 & 24,0 & RS \\
\hline 31 & M & 1,5 & B & CP & 28,0 & 29,0 & RS \\
\hline 32 & M & 2,0 & C & RL & 59,5 & 58,0 & RS \\
\hline 33 & M & 0,5 & C & CP & 33,0 & 38,0 & RS \\
\hline 34 & M & 2,2 & C & $\mathrm{CP}$ & SI & SI & RS \\
\hline 35 & $M$ & 3,0 & C & $\mathrm{CP}$ & SI & SI & RS \\
\hline 36 & M & 1,0 & C & $\mathrm{CP}$ & 35,5 & 40,0 & RS \\
\hline 37 & $M$ & 3,2 & C & RL & 36,0 & 36,0 & RB \\
\hline 38 & $M$ & 2,5 & C & $\mathrm{CP}$ & 33,0 & 25,0 & RB \\
\hline 39 & M & 3,0 & C & CP & 39,0 & 20,0 & RB \\
\hline 40 & $M$ & 2,5 & C & RL & 26,0 & 27,0 & RB \\
\hline 41 & $M$ & 1,2 & C & $\mathrm{CP}$ & 24,0 & 27,5 & RS \\
\hline 42 & $M$ & 2,2 & C & $\mathrm{RL}$ & si & SI & RS \\
\hline 43 & M & 2,5 & B & RL & 39,0 & 35,0 & RS \\
\hline 44 & $M$ & 1,6 & B & RL & 47,0 & 50,0 & RS \\
\hline 45 & $M$ & 0,7 & B & CP & 16,0 & 18,0 & RS \\
\hline $46^{\circ}$ & MJ & 4,0 & B & RL & 20,0 & 21,0 & RS \\
\hline 47 & 1 & 7,8 & C & SI & SI & SI & SI \\
\hline 48 & 1 & 13,4 & concreto & SI & SI & SI & SI \\
\hline 49 & 1 & 10,2 & C & SI & SI & SI & SI \\
\hline 50 & I & 15,0 & C & Si & Si & Si & SI \\
\hline 51 & I & 12,0 & C & SI & SI & SI & SI \\
\hline 52 & 1 & 5,0 & C & SI & SI & SI & SI \\
\hline $1110^{\circ *}$ & FT & 1,0 & C & SI & SI & SI & si \\
\hline $1113^{* 0}$ & FT & 1,0 & C & SI & SI & SI & SI \\
\hline
\end{tabular}

(*) - Dado proporcionado por W. Oveal.

(*) - Dados proporcionados por R. Jeanne. 
nhos se acham orientados a partir de $0^{\circ}$ até o ângulo de $345^{\circ}$. Jeanne (1975a) mediu a orientação dos ninhos de Metapolybia sp., achando que não havia preferência por nenhum ângulo de orientação. Nos ninhos de S. surinama, ao aplicar o teste $X^{2}(Z a r, 1974)$ com $H_{0}$ : na qual se considera que todas as direções provêm de uma população uniformemente distribuída ao redor do círculo e $\mathrm{H}_{1}$ : o contrário, o valor do teste deu resultado significativo, $X^{2}=17,074$ $(\mathrm{P}<0,001)$ : aceitou a $\mathrm{H}_{1}$.

\section{Angulo de inclinação do substrato}

O ângulo de inclinação do substrato determina a inclinação que 0 ninho deve tomar quando construído. Os ninhos de S. surinama podem tomar uma inclinação entre $0^{\circ}$ e $90^{\circ}$ com a abertura de acesso dirigida para acima ou paralela ao solo. Qualquer outra posição fora deste padrão não é característica para os ninhos desta espécie. Na fig. 2, indicam-se os ângulos com que as vespas constroem, mostrando que têm alguma preferência na escoIha do substrato, o que vai determinar o ângu-

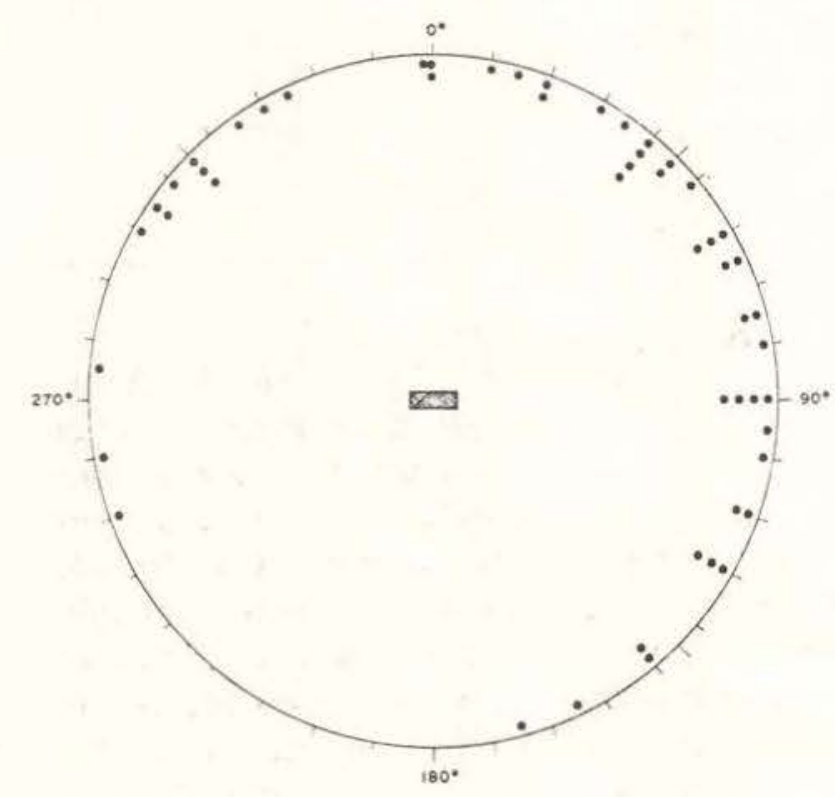

Fig. 1 - Ângulos de orientação dos ninhos de Synoeca surinama com respeito ao polo magnético. Cada ponto representa um ninho. lo de inclinação do ninho. A fig. 2 demonstra, ainda, que o maior número de ninhos (45) encontram-se sobre os substratos com ângulo de inclinação entre $5^{\circ}$ e $45^{\circ}$, e 9 dos ninhos estavam sobre substratos com ânguilos de inclinação entre $46^{\circ}$ e $90^{\circ}$. O valor ã (Zar, 1974) para a distribuição dos ângulos de inclinação é de $58^{\circ}$.

\section{Arquitetura do ninho}

Os ninhos de Synoeca surinama são conhecidos como do tipo astelocítaro. Ninhos do tipo astelocítaro são definidos por Richards (1951) como uma câmara simples fixada diretamente ao tronco, parede ou folha. Um invólucro em forma de cúpula se levanta de ou perto da margem das células. Jeanne (1975c) o define como uma câmara simples, construida diretamente sobre a superficie aplainada e coberta com um invólucro, na qual a entrada é superior.

Dos 54 ninhos coletados, 22 apresentavam só uma câmara, porém, pode-se encontrar ninhos com duas, três e até cinco câmaras. Cada câmara está coberta por um invólucro. O invólucro é na forma de cúpula com corrugações características sobre cada lado da linha média (ou quilha) (Vesey-Fitzgeral, 1938). A forma característica corrrugada do invólucro é dada pelo seu levantamento, a parìir das células-base (') mais periféricas e que mantêm forma hemicircular, formando um arco na margem externa. O invólucro na sua porção média (quilha) apresenta um espessamento médio de $0,68 \mathrm{~mm}(0,45-1,35 \mathrm{~mm} ; \mathrm{n}=10)$ sendo esta região mais forte e resistente lembrando a forma da quilha de um barco. As porções mais laterais do espessamento do invólucro apresentam uma medida média de $0,41 \mathrm{~mm}$ $(0,38-0,47 \mathrm{~mm} ; n=10)$. Em todos os ninhos coletados e que apresentam invólucros em boas condições foram tomadas medidas da largura e comprimento em todas as câmaras. As medidas dos invólucros das várias câmaras de 32 ninhos são dadas na tabela 2 .

Células e células-base no interior de cada câmara apresentam um diâmetro médio de

(1) - Considero célula-base uma célula sem paredes levantadas (= células séssil). 
TABELA 2 - Medidas dos invólucros, largura e comprimento $(\mathrm{cm})$ das câmaras e comprimento total (c) dos ninhos de S. surinama e valores dos ângulos formados pela superposição dos invólucros das câmaras.

\begin{tabular}{|c|c|c|c|c|c|c|c|c|c|}
\hline \multirow[t]{2}{*}{ Ninho } & \multicolumn{2}{|c|}{ Câmara 1} & \multicolumn{2}{|c|}{ Câmara II } & \multicolumn{2}{|c|}{ Câmara III } & \multirow[t]{2}{*}{ Comprimento total } & \multirow{2}{*}{$\begin{array}{l}\text { Ângulo entre } \\
\text { Câmaras I e II }\end{array}$} & \multirow{2}{*}{$\begin{array}{l}\text { Ãngulo entre } \\
\text { Câmaras II e III }\end{array}$} \\
\hline & Comp. & Largura & Comp. & Largura & Comp. & Largura & & & \\
\hline 1 & 36 & 37 & 24 & 39 & 40 & 43 & 100,0 & $45^{\circ}$ & $36^{\circ}$ \\
\hline 2 & 48 & 37 & 26 & 37 & - & - & 74,0 & $23^{\circ}$ & - \\
\hline 4 & 47 & 36 & 32 & 32 & - & - & 79,0 & $45^{\circ}$ & - \\
\hline 5 & 45 & 36 & - & - & - & - & 52,0 & - & - \\
\hline 6 & 52 & 44 & - & - & - & - & 45,5 & - & - \\
\hline 7 & 45,5 & 34,5 & - & - & - & - & 45,5 & - & - \\
\hline 8 & 48 & 37 & 41 & 41,5 & - & - & 89,0 & $31^{\circ}$ & - \\
\hline 19 & 57 & 40,5 & - & - & - & - & 57,0 & - & - \\
\hline 20 & 40 & 30 & - & - & - & - & 40,0 & - & - \\
\hline 21 & 42 & 31 & - & - & - & - & 42,0 & - & - \\
\hline 22 & 41 & 32 & - & - & - & - & 41,0 & - & - \\
\hline 23 & 54 & 39 & 29 & 33,5 & 29 & 33,5 & 112,0 & $36^{\circ}$ & $35^{\circ}$ \\
\hline 24 & 53 & 43 & 38 & 48 & - & - & 91,0 & $53^{\circ}$ & - \\
\hline 25 & 55 & 42,5 & - & - & - & - & 55,0 & - & - \\
\hline 26 & 43 & 36 & - & - & - & - & 43,0 & - & - \\
\hline 27 & 44 & 38 & 40 & 35,5 & - & - & 84,0 & $45^{\circ}$ & - \\
\hline 28 & 53 & 35 & - & - & - & - & 53,0 & - & - \\
\hline 29 & 51 & 45 & - & - & - & - & 51,0 & - & - \\
\hline 30 & 50 & 32 & 45 & 40 & - & - & 95,0 & $30^{\circ}$ & - \\
\hline 31 & 50 & 42 & - & - & - & - & 50,0 & - & - \\
\hline 32 & 55 & 41 & - & - & - & - & 55,0 & - & - \\
\hline 33 & 71 & 55 & - & - & - & - & 71,0 & - & - \\
\hline 36 & 51 & 34,5 & - & - & - & - & 51,0 & - & - \\
\hline 37 & 56 & 48 & - & - & - & - & 56,0 & - & - \\
\hline 38 & 51 & 47,5 & 32 & 42 & - & - & 83,0 & $40^{\circ}$ & - \\
\hline 39 & 36 & 25 & 30 & 45 & - & - & 66,0 & $40^{\circ}$ & - \\
\hline 40 & 50 & 30 & - & - & - & - & 50,0 & - & - \\
\hline 41 & 52 & 45 & - & - & - & - & 52,0 & - & - \\
\hline 43 & 52 & 42 & - & - & - & - & 52,0 & - & - \\
\hline 44 & 50 & 40 & - & - & - & - & 50,0 & - & - \\
\hline 45 & 45 & 47 & - & - & - & - & 45,0 & - & - \\
\hline 46 & 45 & 36 & - & - & - & - & 45,0 & - & - \\
\hline
\end{tabular}

$0,7 \mathrm{~mm}$. As células apresentam diferentes alturas, que variam de acordo com a idade do ninho e o tamanho das larvas ou pupas, se estiverem ocupadas com estes imaturos.

As células mais centrais contendo pupas e com maiores alturas, medem em média 2,78 $\mathrm{cm}(2,73-2,84 \mathrm{~cm} ; \mathrm{n}=20)$. As células-base têm uma altura média de $2,35 \mathrm{~mm}(1,9-2,8$ $\mathrm{mm} ; \mathrm{n}=20$ ). A forma hexagonal é predominante em células e células-base, exceto naquelas que se encontram nas margens e nas quais as paredes externas são semicirculares. Em ninhos velhos, que contêm principalmente imaturos em estado de pupas ou últimos estágios larvais, as células apresentam-se em várias fi- leiras. Rodeando estas fileiras de células encontram-se normalmente duas ou três fileiras de células-base em ambos os lados e superiormente do grupo de células nas diferentes câmaras. Na primeira câmara, as fileiras de células-base apresentam-se lateral e inferiormente. Células e células-base, em todas as câmaras guardam uma mesma orientação em fileiras dada sua forma hexagonal, onde cada lado serve como parede a duas células ou células-base contíguas (Fig. 3).

A tabela 3 agrupa os dados obtidos do número de células e células-base por cada câmara e o número total de células e células-base nos diferentes ninhos coletados. 
Quando existem ninhos com duas ou mais câmaras contíguas, as células e células-base guardam a mesma orientação e disposição em fileiras contíguas em face do que, para a cons-

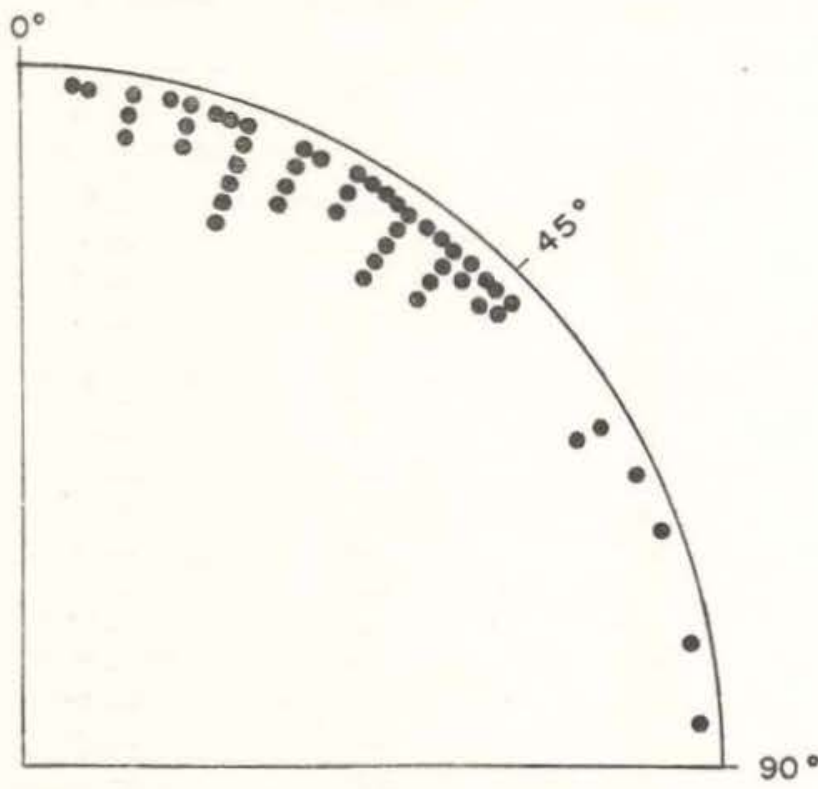

Fig. 2 - Ángulos de inclinação dos ninhos de acordo com a inclinação do substrato. Cada ponto representa um ninho. trução da segunda ou mais câmaras, as ves. pas tomam como padrão as corrugações do in. vólucro imediatamente anterior superpondo 0 novo invólucro e cobrindo a abertura de acesso ao ninho da câmara mais velha com o novo invólucro. A medida que o ninho vai amadurecendo, as vespas destroem a parte superior do invólucro e inferior da região onde se encontrava a entrada de acesso até deixar o invólucro truncado, o que visto frontalmente se assemelha a um arco. Este truncamento do invólucro inferior permite a continuidade da disposição das células, o livre acesso das vespas e a comunicação entre as câmaras contíguas.

\section{Materiais usados na construção}

Para a construção do ninho, é usado material vegetal, que as vespas obtêm raspando com as mandíbulas casca de árvores, líquens e folhas de plantas. O material é mastigado. produzindo um macerado áspero ao tato e com uma coloração parda escura.

Durante a mastigação do material, a água é provida por trofalaxia por outras operárias e

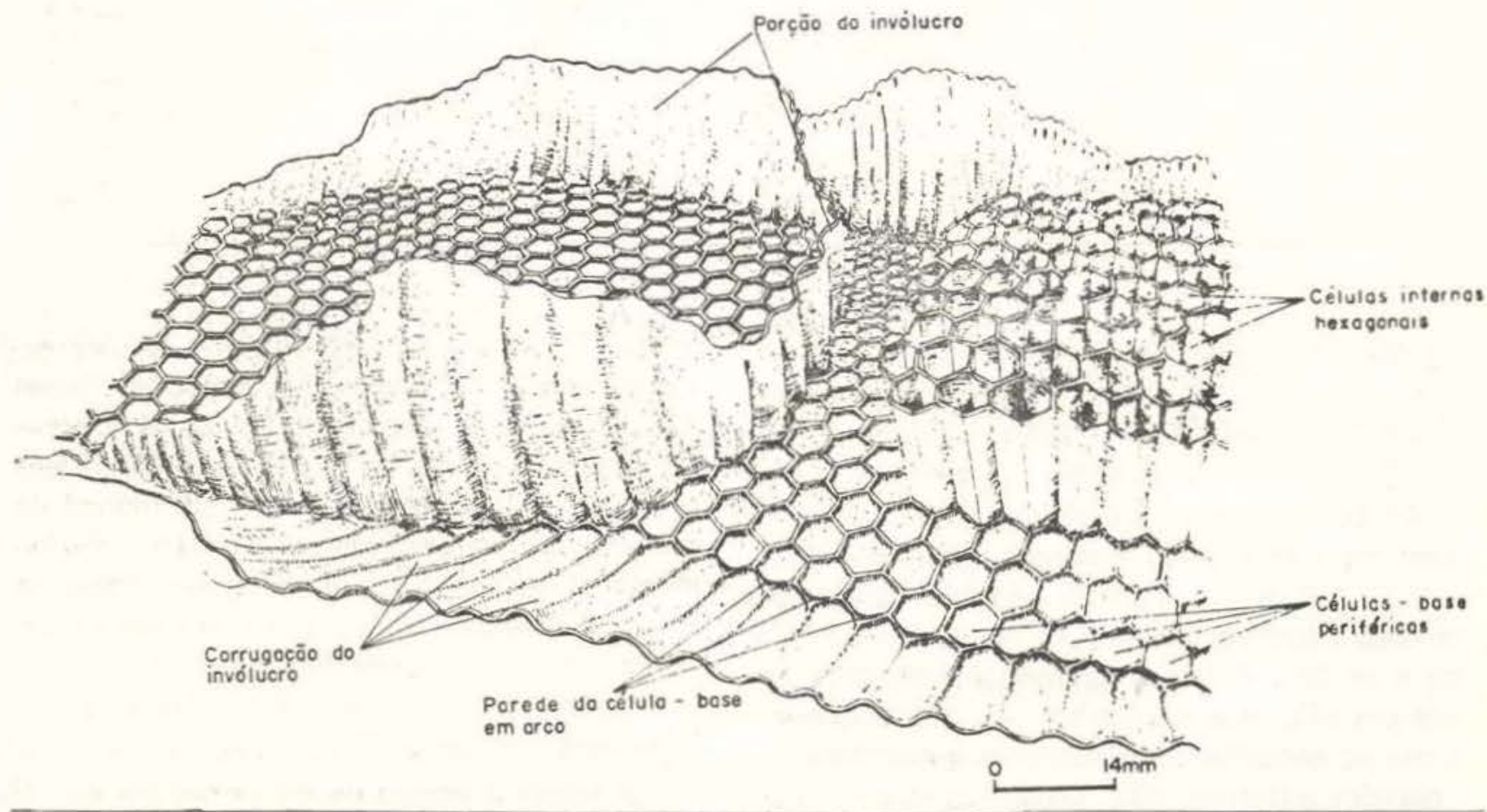

Fig. 3-Vista parcial de uma porção do ninho, assinalando as células mais internas hexagonais, células-bases periféricas com a parede externa em forma de arco e formação das corrugações do invólucro. Observa-se que o invólucro sai da margem das células-base com a parede em forma de arco. 
TABELA 3 - Número das células e células-base (por cânara) e número total de células e células-base nos ninhos de Synoeca surinama.

\begin{tabular}{|c|c|c|c|c|c|c|c|c|}
\hline \multirow{2}{*}{ Ninho } & \multirow{2}{*}{ Câmaras } & \multicolumn{2}{|c|}{ Câmara 1} & \multicolumn{2}{|c|}{ Câmara II } & \multicolumn{2}{|c|}{ Câmara III } & \multirow{2}{*}{$\begin{array}{c}\text { Total células e } \\
\text { células-base }\end{array}$} \\
\hline & & Células & células-base & Células & células-base & Células & células-base & \\
\hline 1 & 3 & 790 & 150 & 341 & 129 & 157 & 130 & 1697 \\
\hline 2 & 2 & 315 & 102 & 120 & 69 & - & - & 435 \\
\hline 4 & 2 & 470 & 155 & 164 & 99 & - & - & 888 \\
\hline 6 & 1 & 432 & 148 & - & - & - & - & 580 \\
\hline 7 & 1 & 156 & 268 & - & - & - & - & 424 \\
\hline 8 & 2 & 594 & 126 & 462 & 150 & - & - & 1332 \\
\hline 19 & 1 & 532 & 192 & - & - & - & - & 724 \\
\hline 20 & 1 & 187 & 120 & - & - & - & - & 307 \\
\hline 21 & 1 & 284 & 202 & - & - & - & - & 486 \\
\hline 22 & 1 & 442 & 109 & - & - & - & - & 551 \\
\hline 23 & 3 & 527 & 167 & 349 & 152 & - & - & 1475 \\
\hline 24 & 2 & 375 & 94 & 242 & 57 & - & - & 768 \\
\hline 25 & 1 & 485 & 179 & - & - & - & - & 664 \\
\hline 26 & 1 & 337 & 125 & - & - & - & - & 462 \\
\hline 27 & 2 & 594 & 157 & 217 & 195 & - & - & 1163 \\
\hline 28 & 1 & 358 & 173 & - & - & - & - & 531 \\
\hline 29 & 1 & 19 & 410 & - & - & - & - & 429 \\
\hline 30 & 3 & 284 & 60 & 238 & 67 & 61 & 52 & 762 \\
\hline 31 & 1 & 457 & 120 & - & - & - & - & 577 \\
\hline 32 & 1 & 432 & 147 & - & - & - & - & 579 \\
\hline 33 & 1 & 632 & 189 & - & - & - & - & 821 \\
\hline 34 & 3 & 495 & 142 & 296 & 74 & 316 & 128 & 2151 \\
\hline 36 & 1 & 797 & 199 & - & - & - & - & 996 \\
\hline 37 & 1 & 653 & 102 & - & - & - & - & 755 \\
\hline 38 & 2 & 521 & 116 & 340 & 94 & - & - & 1071 \\
\hline 39 & 2 & 351 & 122 & 29 & 344 & - & - & 846 \\
\hline 40 & 1 & 335 & 162 & - & - & - & - & 497 \\
\hline 41 & 1 & 279 & 149 & - & - & - & - & 428 \\
\hline 43 & 1 & 252 & 205 & - & - & - & - & 557 \\
\hline 44 & 1 & 179 & 138 & - & - & - & - & 317 \\
\hline 45 & 1 & 272 & 145 & - & - & - & - & 417 \\
\hline 46 & 1 & 354 & 183 & - & - & - & - & 537 \\
\hline
\end{tabular}

provavelmente secreção salivar das glândulas mandibulares. Heselhaus (1922 apud WestEberhard, 1969:85) afirmou: considero as glândulas mandibulares de Polistes como sendo glândulas de construção.

Ao observar ao microscópio estereoscópio pedaços do invólucro de vários ninhos, encontrei presentes líquens, pedaços de casca de árvore de até $6 \mathrm{~mm}$ de comprimento e dispostos de forma irregular junto com partículas de areia, coesos por serragem. Preparações do material observado ao microscópio composto revelaram a presença de tricomas, epiderme superior de folhas, algumas algas unicelulares cianofitas e polem. Os grãos de polem do ninho foram identificados como provenientes das plantas Byrsonina sp. (Malphigeaceae), Alchornea sp. (Euphorbiaceae), Tapirira guianensis (Aubl.) (Anacardiaceae) e uma Melastomataceae de um gênero não identificado. Suas proporções foram respectivamente: $20 \%, 70 \%, 5 \%$ do polem encontrado.

\section{Fundação do ninho}

É característica nas espécies de Polybiini a formação de enxames para migrar e construir novos ninhos. S. surinama não é exceção e como tal foi observada a construção de ninhos por enxames em quatro oportunidades 
(ninhos 1, 2, 19 e 29). Em outras duas ocasiões, foi constatado o aumento do tamanho do ninho (adição de uma nova câmara).

Durante as duas primeiras construções (ninhos 1 e 2), foi relativamente difícil observar diretamente a atividade de construção havendo necessidade de usar binóculos, porém nos ninhos 19 e 29 foi observada mais de perto a construção (entre 20 e $50 \mathrm{~cm}$ ). Algumas vespas desde a chegada do enxame ao substrato e desde o início do ninho até a formação do invólucro formam grupos ( 3 a 4 grupos) e permanecem inativas. Outras vespas encontram-se ativas por toda a área, limpando, buscando material e construindo. No decurso da construção, as operárias agrupadas podem fundir-se em um grupo único e posteriormente subdividir-se novamente. Semelhante comportamento ocorre em $P$. sericea (Fab.) e $P$. occidentalis (Oliv.) (dados não publicados). Como grupos de trabalho, as vespas ativas começam a construir iniciando as células-base. As primeiras células-base, em todos os casos observados, são construídas simultaneamente, sendo difícil determinar qual foi a primeira construída. Ao trabalhar em conjunto, as vespas chegam a construir mais de dez células-base inicialmente.

Em outros Polybiini, como Polybia sericea e Polybia occidentalis, o início do ninho é também por colaboração entre as várias operárias que formam o enxame.

$A$ adição de novas células-base faz-se a partir dos vértices das células-base pré-construídas e contíguas determinando os lados como padrão para as novas células-base do tipo hexagonal. Este tipo de célula foi definido por Jeanne (1973: 187) como:

...célula séssil, início de uma célula sobre uma superficie para formar um cilindro ou um hexágono. cujas paredes são perpendiculares e unidas diretamente a essa superfície, que pode ser o substrato, ou que pode ser uma parte do mesmo ninho. O substrato então forma o assoalho da célula.

Desta forma e de acordo com a definição anteriormente citada, inicia-se a construção das células-base nos ninhos de $S$. surinama.

Quando são construídas as primeiras células-base sobre o substrato, as vespas come- çam a expandir a construção, agregando lateralmente mais células-base, construindo a parte superior e inferior até produzir um grande número de células-base. Cada operária gasta em média 5 minutos para construir uma célula-base. Em muitos casos, a mesma operária constrói 3 a 4 células-base em fileira gastando de 15 a 20 minutos na construção. Várias operárias podem agrupar-se para construir mais de 5 células-base. Por exemplo, 5 operárias agrupadas constroem 10 células-base em 60 minutos. A média das operárias construindo os ninhos 19 e 29 foi de 39 por hora de atividade de construção ( 7 dias).

\section{Formação do primeiro invólucro}

Muitas espécies de vespas constroem ninhos com invólucro. Isto deu base a vários autores como Saussure (1858 em Richards \& Richards, 1951), lhering (1904), Jeanne (1975c) e West-Eberhard (1975) para classificar os diferentes tipos de ninhos.

A descrição de várias fases de construção de invólucros em muitas espécies tem sido realizada por vários autores. Vesey-Fitzgerald (1938), por exemplo, descreveu com poucos detalhes a construção do invólucro de $S$. surinama. O levantamento do invólucro inicia-se no terço superior da construção, que mais tarde será a primeira câmara. Pode observar-se que durante este estado da construção, o maior número de células-base encontram-se no terço superior mais do que na região inferior. 0 levantamento é progressivo e simétrico em ambos os lados do conjunto de células-base, continuando até as regiōes superior e inferior com um ligeiro declive e menor altura na inferior que no terço superior visto que nesta região foi iniciado o levantamento. A medida que constroem vão moldando o invólucro em uma forma curvada para o interior.

Progressivamente, as vespas continuam adicionando faixas de material até começar a delinear um semi-círculo na parte superior. A medida que adicionam material, vão estreitando as faixas no terço superior para completar o círculo, que vai servir como abertura de acesso ao ninho. Até formar uma curta projeção ao exterior de uns $4 \mathrm{~mm}$ de altura, com 
uma média de $2,25 \mathrm{~cm}(2,00-2,50 \mathrm{~cm} ; \mathrm{n}=5)$ de diâmetro e uma espessura de $0,852 \mathrm{~mm}$ $(0,75-105 \mathrm{~mm} ; \mathrm{n}=5)$. A formação do invólucro, a partir da adição do material em forma de faixas, segue sempre uma forma curva, encontrando ou fechando as partes inferiores posteriormente, à medida que avança a construção (Fig. 4). Nos quatro ninhos, cuja construção foi observada na sua totalidade e nos dois outros que adicionaram uma nova câmara, houve o mesmo procedimento, dando-se a confirmação de que constroem de acordo com um padrão, isto é, obedecendo a vários pontos de referência. Estes pontos de referência são:

a) Levantamento, a partir das célulasbase.

b) Iniciação do invólucro no terço superior.

c) Adição do material em faixas e em forma triangular.

d) Delineamento da abertura de acesso e posterior adição de material, a partir da abertura de acesso.

$\mathrm{Na}$ porção inferior do ninho não existem células-base em fileiras contínuas que possam servir de padrão para o levantamento do invólucro. Nesta região, as vespas constroem somente uma fileira de células-base ou similar e, a partir desta, procedem ao levantamento do invólucro.

\section{Aumento do tamanho do ninho e formação do segundo invólucro}

No início da construção do ninho, as primeiras células-base construídas foram as mais centrais e a expansão foi realizada em todas as direções. $\mathrm{O}$ aumento de tamanho do ninho (pela adição da segunda câmara) é iniciado com a construção de células-base a partir da região superior do primeiro invólucro e o número de células-base é incrementado em direção à parte superior.

A parede do primeiro invólucro na região superior atua como uma barreira entre as células-base da primeira câmara e as células-base da-segunda câmara. Este primeiro invólucro é o padrão para as células-base da segunda câmara.

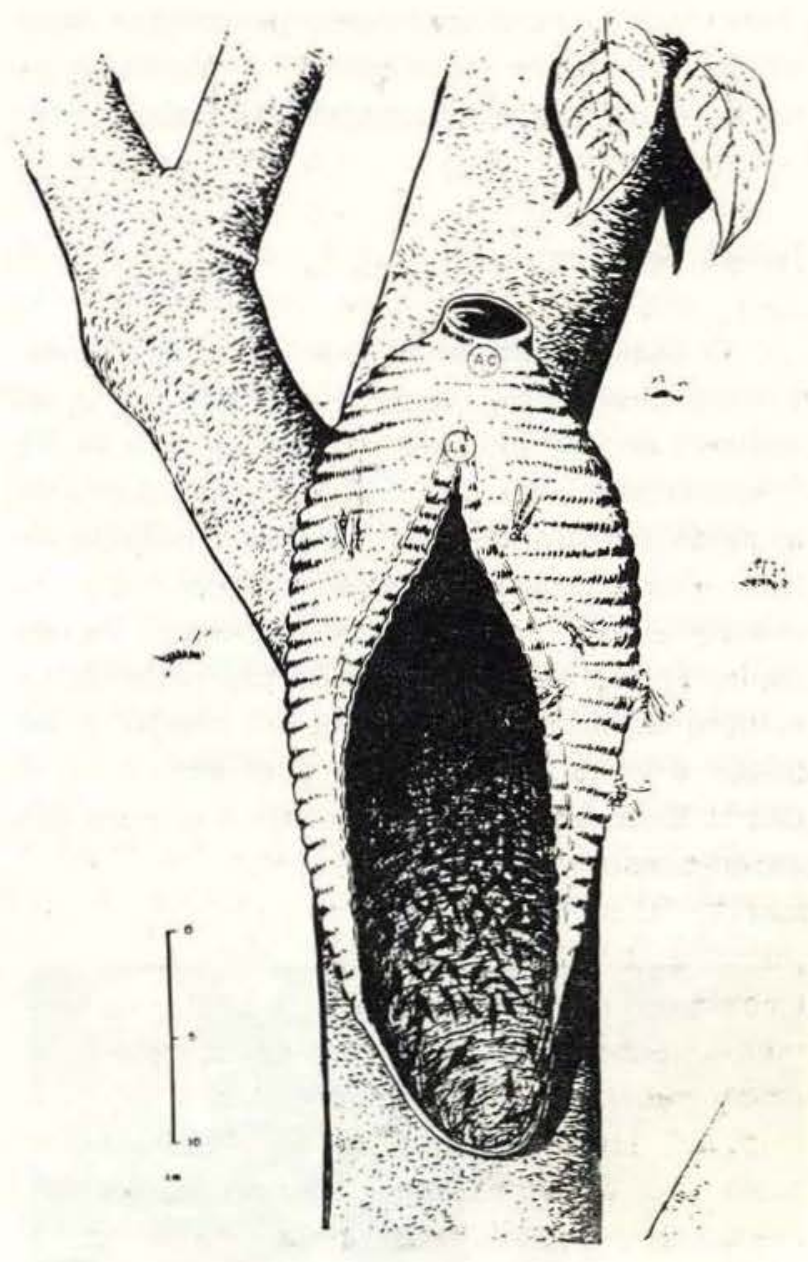

Fig. 4 - Vista frontal de um ninho parcialmente construido. (AC) Abertura de acesso circular. (LS) Linha semicurva para adição da polpa em forma de faixas triangulares a partir da abertura de acesso que serve de padrão para o fechamento do invólucro.

Para o início e formação das células-base da segunda câmara e segundo invólucro, as vespas seguiram o mesmo padrão que na primeira câmara. Na região onde as câmaras se comunicam, o invólucro da segunda câmara está superposto ao da primeira a uma altura maior que alcança até $5 \mathrm{~cm}$ de altura a mais, formando lateralmente um ângulo entre os dois invólucros superpostos.

Os valores dos ângulos formados pela superposição dos invólucros em ninhos de duas ou três câmaras estão relacionados na tabela 2. Uma nova abertura de acesso é construída sobre a região superior do segundo invólucro. 
Uma terceira e mais câmaras podem ser construídas em forma semeihante à segunda câmara. A figura 5 mostra um ninho já acabado com duas câmaras.

\section{Tempo de construção}

O tempo durante o qual as vespas construiram a primeira câmara (células-base e invólucro) foi em média 7 dias $(6-8 ; n=4)$. A elaboração das células-base e invólucro da segunda câmara foi realizado num período de dias. A segunda câmara dos ninhos 1 e 2 foi iniciado 4 e 5 dias, respectivamente, depois de haver realizado a formação completa do invólucro da primeira câmara. Entretanto, a segunda e terceira câmaras podem ser construídas 15 dias depois de construída a câmara que as antecede.

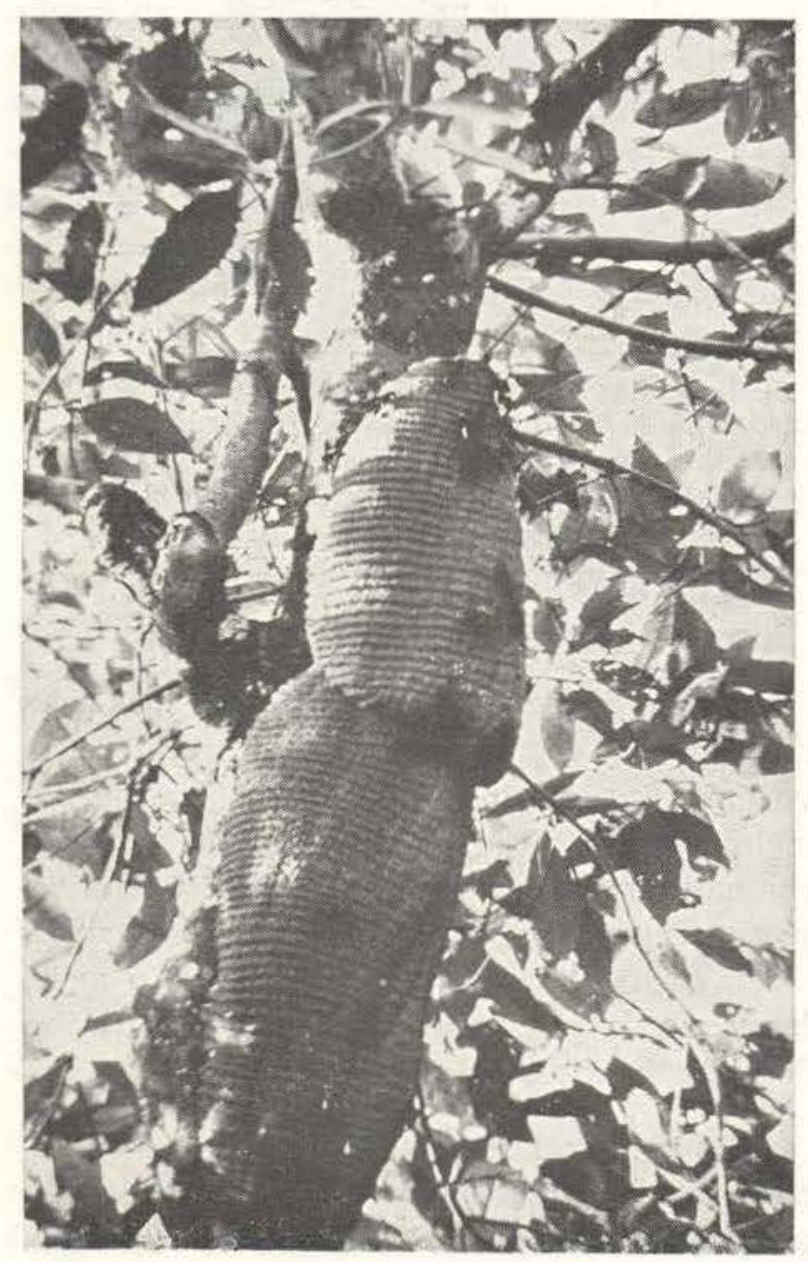

Fig. 5 - Ninho de $\mathbf{S}$. surinama com duas câmaras.
No ninho número 1, a terceira câmara foi construída em 8 dias e foi iniciada 19 dias depois de ser construída a primeira.

\section{Manutenção do ninho}

Quando há danos sobre o invólucro, causados por predadores, e pelo homem ou chuvas, as vespas começam a repará-los quase que imediatamente. Porém, em geral, quando reparam o estrago, fazem-no como se estivessem construindo o ninho originalmente. Entretanto, já não guardam o mesmo padrão de orientação nas ondulações ou corrugações do invólucro. As áreas reparadas não têm a mesma forma original e são produzidas saliências ou concavidades sobre o invólucro.

Em mais de dez oportunidades, durante a noite, o invólucro de um mesmo ninho foi danificado do experimento mentalmente fazendn perfurações de $15 \mathrm{~cm} \times 10 \mathrm{~cm}$ (medida aproximada). No outro dia, as vespas procediam à reconstrução do ninho. Em todos os casos. sempre houve reparação do dano no ninho. Quando o ninho está habitado, a manutenção da construção é constante, sendo que as vespas reparam qualquer dano produzido.

\section{Discussão}

Existe, de acordo com os valores dados na Fig. 1, uma padronização na orientação dos ninhos. A preferência mostrada na Fig. 2 para a escolha do substrato, onde $84,9 \%$ dos ninhos foram construídos com uma inclinação que flutua entre $10^{\circ}$ e $45^{\circ}$ conjuntamente com a escolha do ângulo de orientação do ninho, demonstra que há uma resposta mecânico-comportamental na posição das crias, na velocidade e direção dos ventos e volume de chuvas.

Ninhos construidos em ramos laterais e próximos da bifurcação destes, teoricamente receberiam uma proteção mais efetiva contra fatores ambientais adversos e seriam ocultos de predadores aéreos, entretanto, não parece haver qualquer preferência por estas alternativas protetoras. Da tabela 2 , se deprende que somente 25 ninhos foram construídos sobre 
ramos laterais e 19 sobre o tronco principal, 2 foram construídos sobre uma ripa de madeira de $5 \mathrm{~cm} \times 5 \mathrm{~cm}, 14$ ninhos foram construídos de uma bifurcação e em 32 não existila bifurcação perto dos gaihos em cima do ninho. Segundo estes dados, não existe preferência pela forma protetora simples ou bifurcada do substrato; existe, sim uma preferência pela inclinação do substrato, o que lhes permite igual proteção.

Algumas espécies podem mostrar preferências ao escolher o lugar para nidificar. Jeanne $(1973,1975 b)$ encontrou 7 ninhos de Stelopolybia areata todos construídos sobre pequenos ramos e próximos da cobertura da árvore em que se encontram, além de que os ramos tomavam posição mais vertical do que horizontal. Em Melapolybia, notou que as colônias construíram os ninhos em dois lugares: sobre árvores Guilielma utilis (Palmae) e próximos de casas, sempre em alturas semelhantes numa mesma área, porém em alturas diferentes em diferentes áreas, mostrando tendências a construir, buscando maior proteção contra fatores climáticos.

Jeanne (1973) notou que no início da construção do ninho de Stelopolybia areata existem três tipos de células: peciolada, que em síntese consiste na construção da célula sobre um filamento. Este tipo de célula é usado no início do ninho de M. drewseni (Jeanne, 1972). O tipo de célula séssil que é o descrito para S. surinama e o tipo lateral, quando a célula é construída a partir de uma célula pré-existente, formando ângulo com outras paredes e curvando-se em $90^{\circ}$ para formar a parede da nova célula.

A célula mais econômica e mais fácil de ser construída aparentemente é a do tipo séssil, cada espécie ao iniciar a construção do ninho apresenta alternativas adaptativas na arquitetura de seu ninho, o que não permite afirmar qual tipo seria comumente mais vantajoso, sob o ponto de vista funcionai e de construção, de acordo com a arquitetura, evolução da forma e estratégias adotadas por cada espécie para superar desvantagens, dada a pressão de predadores e do ambiente.
O número inicial de células construídas nas diferentes espécies varia. Em espécies monogínicas, as células são iniciadas por uma rainha fundadora, com uma média de 30 a 40 células para rainhas de Polistes (Marimoto, 1954 apud Spradbery, 1965). Brian \& Brian (1952) observaram que em Vespula sylvestris, o incremento no número de células ocorre antes da eclosão da primeira operária, com médias de construção de 2,3 e 1,7 células por dia em dois ninhos. Em Polybiini, em espécies que formam enxames, a construção das células é por colaboração entre os indivíduos da colônia. Em S. surinama foi observado o tempo de construção, número de indivíduos envolvidos na construção e número de células construídas. Por exemplo: em 1 hora, 5 vespas constroem 10 células-base, em 20 minutos uma vespa constrói 3,5 células-base, em 18 minutos uma vespa constrói 2,5 células-base, em 10 minutos duas vespas constroem 4 célulasbase.

Autores como Jeanne $(1972,1975 \mathrm{C})$ em M. drewseni e outros Polybiini, Buysson (1906) em Apoica e Synoeca, Dow (1939) em várias espécies de vespas da Inglaterra e WestEberhard (1975) em 16 espécies de Polybiini da Colombia discutiram aspectos do início, evolução e freqüências de construção de células nos ninhos.

Predação é uma das causas principais de migração e abandono dos ninhos pelas colônias de vespas. As vespas, portanto, têm sido selecionadas para as estratégias que permitam a sua sobrevivência e a de suas crias. Jeanne (1975c) opinou que a predação pelas formigas é um dos maiores fatores que mais contribuem na evolução dos ninhos.

Possivelmente, espécies de Mischocyttarus e Polistes com nínhos não cobertos pelo invólucro adaptaram como uma estratégia na defesa do ninho a aplicação de substâncias repelentes no pedicelo do ninho, o que ameniza 0 ataque por parte de predadores que usam esta passagem para invadir o ninho (WestEberhard, 1969; Jeanne, 1970, 1972). Outras espécies de Vespinae e Polybiini constroem os ninhos com invólucro. É o caso da maioria das espécies sociais, que evolutivamente não 
parecem ter desenvolvicio uma capacidade de produzir substâncias repelentes ou outro tịpo especial de estratégia. O invóiucro destas espécies têm um significado muito grande na estratégia de defesa. O invólucro minimisa e dificulta a predação da cria pelos predadores aéreos e em caso de inimigos invadirem o ninho pela abertura de acesso como em ninhos de $S$. surinama, geralmente há operárias defendendo a entrada.

O invólucro tem o padrão básico das células por iniciar na última fileira de células-base. Sua forma não varia em áreas que não apresentam células ou células-base. As ondulações ou corrugações do invólucro são um pouco mais pronunciadas nos extremos do que nos lados e na parte superior do invólucro. visto que a parte basal é iniciada depois de começar as células-base. As ondulações na parte superior resultam da expansão das paredes periféricas. Jeanne (com. pessoal) opina, a respeito, que na construção do invólucro, as vespas de $S$. surinama fazem meia célula nas células periféricas, usando o mesmo comportamento de quando constroem células completas. A medida média da largura da célula e da ondulações do invólucro é de $7 \mathrm{~mm}$.

O invólucro dos ninhos de $S$. surinama na sua parte central longitudinal apresenta uma projeção (semelhante a quilha de um barco) que permite enfrentar situações ambientais adversas com bastante êxito: a chuva por exemplo, não golpea diretamente o invólucro mas sim o substrato e a água pode deslisar pelos lados do invólucro e pode ser canalizada pelas corrugações até a parte central ou quitha onde o invólucro é mais forte e por onde a água escoa com maior facilidade. A mesma quilha, em caso de ventos fortes, pode ter a mesma facilidade de desviar o vonto que pode chegar frontalmente ao ninho, atuando da mesma maneira de, quando as chuvas incidem sobre o ninho, porém em sentido inverso. $O$ invólucro contribui como meio de comunicação entre as vespas para produzirem alarme e como defesa do ninho.

Os ninhos do tipo astelocítaro, como de Synoeca, apresentam uma grande vantagem em sua construção, isto é economia de mate- rial. Jeanne (1975c), escreveu: "uma vantagem deste tipo de ninho consiste em sua economia de material. O invólucro não necessita ser reforçado além de sua unidade de espessura primária desde que suporte seu próprio peso. 0 substrato provê o fundo e o suporte direto de cada célula".

As vespas constroem ninhos com uma grande variedade de materiais; vespas solitárias como Eumenes, Odynerus, Stenogaster e S. micans constroem ninhos (em realidade são células únicas ou agregadas) com barro; Zethus, também uma vespa solitária, constrói ninhos com fragmentos de folhas, madeira e barro, (Spradbery, 1963; Richards \& Richards, 1951). Vespas sociais constroem ninhos com material vegetal. Polybia emaciata (Lucas) e $P$. singularis e $P$. spinifrons são as três únicas espécies de Polybiini que constroem ninhos com barro (Ihering, 1904; West-Eberhard, 1975; Windsor, 1976; Richards, 1978). Em Metapolybia aztecoides, $M$. cingulata e em algumas espécies de Mischocyttarus, os ninhos são construídos com material vegetal agregando uma secreção transparente, formando janelas no invólucro e adicionando líquens e outros materiais. Em Apoica, é peculiar a fabricação de ninhos com tricomas e folhas tenras (Richards \& Richards, 1951; West-Eberhard, 1975), Outros autores como Vesey-Fitzgerald (1938), Jeanne (1972), MacDonald e Matthews (1976), e West-Eberhard (1969) descreveram o material com que os ninhos de vespas sociais são construídos.

Ihering (1904) escreveu o papelão é uma massa preparada com tecidos vegetais, cascas de árvores, folhas, tricomas e embebidos em quitina. Richards \& Richards (1951) anotaram a caracteristica das vespas sociais é fazer seus ninhos de material vegetal e continuam há considerável variação na qualidade do papelão feito pelos vespideos.

Descrições da construção, arquitetura do ninho e adaptações evolutivas foram feitas por Ducke (1904), Ihering (1904), Buysson (1906), Bertoni (1912), Rau (1929), Vesey-Fitzgerald (1938), Schwarz (1931), Dow (1939), Spradbery (1965), West-Eberhard (1969), Jeanne (1972. 1973, 1975), Richards (1971), MacDona!d et al. 
(1975) e MacDonald \& Mathews (1976), para várias espécies de Vespidae.

\section{CONCLUSÕES}

O comportamento durante a construção (como o início do invólucro no terço superior. adição do material em faixa e em forma triangular, o delineamento da abertura de acesso e posterior adição do material para o encerramento do invólucro, a partir da abertura de acesso) são fortes evidências indicativas de padrão de construção por parte desta espécie e da arquitetura do ninho, o que traz vantagens adaptativas protetoras.

\section{Agradecimentos}

Quero manifestar o meu agradecimento às pessoas e entidades que colaboraram para a realização deste trabaiho: CNPq; INPA, MPEG, FUA. Drs. Warwick E. Kerr, Robert L. Jaenne, Jorge R. Arias, Norman D. Penny, W. L. Overal e, em especial, as Sras. Erica Hagmann e Violeta Hagmann e Srs. Walter e Wilton Hagmann da Fazenda Taperinha. E ao colega Miguel Petrere Junior.

\section{SUMMARY}

The overall aspects which were covered about Synoeca surinama (L): the "habitat" of the species, preferences shown in its choice of the angle of orientation and the angle of inclination of the substrate as a means of protection; the nests construction following charcteristic patterns the model and expansion of the base cells; the standarzation in the construction, measurements and form of the involucre, beginning with walls of the most peripheral base cells, which for a bow the external border; the opening of the circular approach which is the reference point in the finalization of the involucre up to its closing.

Furthermore, it is included: material used in hive construction and the architecture of the hive as defense strategy against predation and parasitism and the brood protection.

\section{BIBLIOGRAFIA}

BERTONI, A.W.

1912 - Contribución a la biologia de las avispas y abejas del Paraguay. An. Mus. nac. Hist. nat. Buenos Aires, 15 (22): 97-146.
BRIAN, M. \& BRIAN, A.D.

1952 - The wasp, Vespula sylvestris Scop.: feeding. foraging, and colony development. Trans. R. Ent. Soc. Lond., 103 (1): 1-26.

BUYSSON, R, DU

1906 - Monographie des vespides appartenant aux genres Apoica e Synoeca. Ann. Soc. ent., Paris, 75: 11-18.

DUCKE, A

1904 - Sobre as vespidas sociais do Pará. Bol. do Mus. Goeldi, 4: 317-374.

Dow, R.P.

1939 - The nests of New England wasps. Buil. Boston Soc. of Nat. Hist., 56: 11-16.

GóEs, R.M.

1976 - Aspectos climatológicos de Manaus. Acta Amazonica 6 (2): 229-233.

IHERING, $R$. VON

1904 - As vespas sociais do Brasil. Revist. Mus. Paulista. 6: 97-309

JEANNE, R.L.

1970 - Note on bat (Phylloderma stenops) preying upon the brood of a social wasps. J. Mammal., 51: 624-625.

1972 - Social biology of the neotropical wasps Mischocyttarus drewseni. Bull. Mus. Comp. Zool., 144 (3): 63-150.

1973 - Aspects of the biology of Stelopolybia areata (Say) (Hymenoptera: Vespidae). Biotropica, 5 (3): 183-198.

$1975 a$ - Nest site selection by Metapolybia in Costa Rica (Hymenoptera: Vespidae). J. Kans. Entomol. Soc. 48 (3): 285-290.

$1975 \mathrm{~b}$ - Social biology of Stelopolybia areata (Say) in Mexico (Hymenoptera: Vespidae). Insectes sociaux, 22 (1): 27-34.

$1975 \mathrm{c}$ - The adaptivness of social wasps nest architecture. O. Rev. Biol., 50: 267-287.

MacDonald, J.F. \& Mattews, R.W.

1976 - Nest structure and colony composition of Vespula vidua and $\mathbf{V}$. consobrina (Hymenoptera: Vespidae). Ann. Entomol. Soc. Amer. 69 (3): $471-475$.

MACDONALD, J.F.; AKRE, R.D. \& HILL, W.B.

1975 - Locations and struture of nests of Vespula atropilosa, and V. acidica (Hymenoptera: Vespidae) J. Kans. Entomol. Soc. 48 (1): 114-121.

RAU, P.

1929 - The nesting habits of the (bald-faced hortnet, Vespa maculata. Ann. Entomol. Soc. of Amer., 22: 659-675.

RICHARDS, O.W.

1971 - The biology of the social wasps.: (Vespidae). Biol. Rev, 46: 483-528.

1978 - The social wasps of the Americas. British Museum (Nat. History). London VH +580 . 4 pls. 
RICHARDS, O.W. \& RICHARDS, M.J.

1951 - Observations on the social wasps of South America (Hymenoptera: Vespidae). Trans. R. Ent. Soc. Lond., 102 (1): 1-169.

SCHWARZ, H.F.

1931 - The nest habits of the diplopterous wasp Polybia occidentalis variety scutellaris (White) as observed at Barro Colorado, Canal Zone. Amer. Mus. Novit., 471: 1-27.

SPRADBERY, J.P

1965 - The social organization of wasp comunities. Sym. Zool. Soc. London, 14: 61-96.

VESEY-FitzGerald, D.

1938 - Social wasps (Hymenoptera: Vespidae) from Trinidad, with a note on the genus Trypoxylon Lat. Trans. R. Ent. Soc. London, 87 (7): 181-191.
WEST-EBERHARD, M.J.

1969 - The social biology of Polistine wasps. Misc. Publi. Mus. Zool. Univ. Michigan, 140: 1-101.

1975 - Estudios de las avispas sociales (Hymenoptera: Vespidae) del Valle del Cauca. 1. Objetivos, métodos y notas para facilitar la identificación de las especies comunes. Cespedesia 4 (16): 245-265.

WINDSOR, D.M.

1976 - Bird as predators on the brood of Polybia wasps (Hymenoptera: Vespidae) in a Costa Rica deciduous forest. Biotropica, 8 (2): 111-116.

ZAR, J.H

1974 - Biostatistical Analysis. Prentice-Hall, Inc., Englewod Clisffs, N. J. 620 p.

(Aceito para publicação em 14/06/80) 